$\begin{array}{ll} & \text { Etnográfica } \\ \text { etnográfica } & \text { Revista do Centro em Rede de Investigação em }\end{array}$

Antropologia

vol. $12(1) \mid 2008$

Vol. $12(1)$

\title{
Nomes Sanumá entre gritos e sussuros
}

Sanumá names between cries and whispers

\section{Alcida Rita Ramos}

\section{CpenEdition \\ Journals}

\section{Edição electrónica}

URL: https://journals.openedition.org/etnografica/1606

DOI: 10.4000/etnografica.1606

ISSN: 2182-2891

\section{Editora}

Centro em Rede de Investigação em Antropologia

\section{Edição impressa}

Data de publição: 1 maio 2008

Paginação: 59-69

ISSN: 0873-6561

Refêrencia eletrónica

Alcida Rita Ramos, «Nomes Sanumá entre gritos e sussuros», Etnográfica [Online], vol. 12 (1) | 2008, posto online no dia 19 junho 2012, consultado o 10 fevereiro 2022. URL: http://

journals.openedition.org/etnografica/1606 ; DOI: https://doi.org/10.4000/etnografica.1606

\section{(c) (i) (9)}

Etnográfica is licensed under a Creative Commons Attribution-NonCommercial 4.0 International License. 


\section{Nomes Sanumá entre gritos e sussuros}

\section{Alcida Rita Ramos}

Como os demais indígenas Yanomami, os Sanumá (o subgrupo mais setentrional dessa família lingüística amazônica) praticam com afinco o sigilo dos nomes próprios. No entanto, ao contrário dos outros, eles praticam também a suspensão do sigilo quando se trata de "fazer coisas com nomes", para parafrasear J.L. Austin. Transformados em ferramentas sociais, os nomes sanumá são capazes de marcar o público com recursos do privado. Assim, alguns poucos nomes masculinos são retirados de seu sigilo doméstico para anunciar o surgimento de grupos patrilineares com os quais os Sanumá organizam sua vida política e matrimonial. Com o advento do conquistador, nomes estrangeiros começaram a entrar no léxico social dos Sanumá, aliviando, assim, a pressão sobre a quebra de sigilo onomástico. Primeiro missionários protestantes, com seus Davis e suas Saras, depois garimpeiros e outros aventureiros da mata, com seus regionalismos e alcunhas idiossincráticas - Ceará, Paraíba, Passarão, etc. - têm contribuído substancialmente para que os nomes sanumá fiquem cada vez mais preservados do ouvido público. Pareceria, então, não ser mais necessário sussurrar nomes para identificar as pessoas, podendo-se agora chamá-las aos gritos. No entanto, as coisas não se passam bem assim. De que modo a etiqueta dos nomes tem reagido a essas mudanças é o que tentarei esquadrinhar aqui.

PALAVRAS-CHAVE: Yanomami, Sanumá, nomes, organização social, contato interétnico.

\section{INTRÓITO}

Não será de estranhar se os leitores se perguntarem o que faz este texto no meio de apelidos, alcunhas e outras designações portuguesas, pois, embora alguns nomes da língua portuguesa por fim apareçam, dá-se ênfase ao sistema de nomeação própria dos índios Sanumá (Yanomami) do extremo norte do Brasil. A maior justificativa para esta inclusão advém de um dos predicados mais úteis e consagrados da antropologia, qual seja, o poder analítico da comparação, e quem diz comparação diz também contraste. Nada que seja produto da criação humana é tão alheio a nós que nos impeça de perceber pontos 
de convergência ou de divergência produtiva quando investimos na força da diversidade cultural para nos compreendermos melhor. É o caso dos Sanumá e do uso que fazem de seu repertório onomástico. Nada na nossa experiência lusófona nos prepara para entender um sistema tão distante como aquele. No entanto, ao tentar entendê-lo em seus próprios termos, percebemos que há, sim, substratos lógicos que o ligam ao nosso modo de classificar pessoas, ainda que aparentemente irreconhecíveis. O mais óbvio deles é o gosto por classificar seres que, em si mesmos, pouco têm que os distingam uns dos outros. Menos visível é o modo como uma sociedade reutiliza um código de classificação para dizer algo mais, abrindo uma fresta para áreas mais recônditas da vida social. Assim como nos demais artigos deste número de Etnográfica em que os autores vão muito além da superfície dos nomes próprios, também aqui, embora de uma forma que nos é muito menos familiar, surpreendemos os Sanumá usando seus secretos nomes para desnudar regiões culturais que, por uma série de complexas razões, preferem manter em discreta obscuridade. No decorrer do texto espero poder demonstrar, primeiro, como tudo isso ocorre no contexto sanumá e, segundo, porque a velha e boa comparação antropológica ainda é uma ferramenta respeitável para desentranhar o que há de arcano aos olhos do observador.

\section{GRITOS}

O nome Pokaima atravessou a aldeia no grito estridente da missionária-enfermeira estadunidense e foi cair nos ouvidos contrangidos de quem ouvia. Todos silenciaram menos a antropóloga residente que depois foi tirar satisfações da outra forasteira. Pois, contestei, ela não sabia que não se deve pronunciar, muito menos aos berros, o nome de pessoas, principalmente adultas e maduras, como o homem que ela chamou? Enquanto, à guisa de defesa, a americana afirmava que não sabia dessa etiqueta - afinal, todos por ali sabem os nomes de todos -, as pessoas na aldeia se divertiam com os meus zelos extremados pelo respeito cultural. Na verdade, aquela missionária, como os demais de seu grupo, poupava-se de uma caminhada de uns 100 metros da "enfermaria" da missão à casa onde se hospedava o dono daquele nome. A política desses evangélicos da MEVA (Missão Evangélica da Amazônia) tem sido desde o início quando se instalaram na região do Alto Rio Auaris nos anos 60, tentar inserir os índios nos horários e locais pré-esbelecidos para a dispensa de medicamentos, numa tentativa de lhes imprimir uma disciplina foucaultiana mal disfarçada.

Alguns anos antes, por volta de 1970, naquela mesma aldeia de Auaris, duas meninas corriam em volta das casas perseguindo-se mutuamente e se chamando nomes. Que nomes? Os nomes dos respectivos pais. Nas horas mortas do dia, os adultos estavam ausentes nas fainas diárias, a antropóloga residente como que de plantão a supervisionar a normalidade da aldeia, e as meninas, 
livres e soltas para expressar seus respectivos agravos. Saber que eu estava lá para ouvir era parte fundamental da eficácia das suas ofensas mútuas. Àquela altura eu já conhecia o suficiente dos hábitos locais para apreciar plenamente o que assistia. Os ingredientes que davam sentido ao incidente estavam todos lá: ausência dos censores adultos, presença da estrangeira, clima de agonismo infantil e um vocabulário onomástico pronto para usar. Calhou-me muito bem a brincadeira, porque era, justamente, o dado estratégico que vinha dar tempero àquela fase da pesquisa e me fazer saborear com mais gosto o fruto proibido que me desafiava: os nomes sanumá e seus segredos.

Desde a época em que preparava o projeto de pesquisa, ainda como estudante de doutorado na Universidade de Wisconsin, eu sabia que iria encontrar segredo dos nomes próprios entre os Yanomami. Mas foi já no campo que me dei conta de que, para sorte minha, esse segredo é muito mais brando entre os Sanumá, o subgrupo da minha escolha, do que entre os outros segmentos Yanomami espalhados pelo norte do Brasil e sul da Venezuela. Enquanto Napoleon Chagnon (1968) e Bruce Albert (1985) descrevem a total intransigência dos Yanomamö e Yanomaë, respectivamente, em pronunciar ou ouvir os nomes dos seus próximos em público, quer sejam vivos ou mortos, machos ou fêmeas, velhos ou novos, eu pude até eleger os nomes como um subprojeto da minha pesquisa sobre organização social. Essa maior tolerância dos Sanumá mostrou-se crucial para eu entender não só a mecânica dos nomes, mas, principalmente, a sua dinâmica e íntima conexão com o modo sanumá de ser Yanomami. É essa ambigüidade dos Sanumá para com os seus nomes, ora esconder, ora expor, que quero explorar aqui, uma vez que é na ambigüidade temporal e espacial que encontro o nexo da forma sanumá de se organizar social e politicamente.

Se os nomes pessoais são sigilosos, para que servem, então? Os Sanumá que me instruíram no assunto diziam que o nome de uma pessoa é um aspecto da sua vulnerabilidade: um xamã pode tomar o nome de um desafeto e manipulá-lo magicamente, causando a morte da vítima. Quatro décadas depois, uma estudante de doutorado sob minha orientação (hoje a doutora em antropologia Silvia Guimarães), em sua pesquisa etnográfica sobre cosmologia sanumá (Guimarães 2005), soube na mesma aldeia que me acolhera que um ente malévolo, de que existe uma profusão no mundo sanumá, se especializou em roubar os nomes das pessoas, escrevê-los num caderno, provocando, assim, a morte dos seus portadores. (Quero fervorosamente crer que qualquer semelhança com a antropóloga bisbilhoteira dos anos 70 nada mais seja do que mera e desditosa coincidência).

Num outro registro, é nitida a associação do nome com a privacidade: chamar uma pessoa diretamente pelo seu nome sanumá equivale a surpreender alguém no ato íntimo de tomar uma ducha. Durante minha pesquisa de campo assisti a um número suficiente de reações de profundo constrangimento ao ver 
o próprio nome desnudado para configurá-las como situações de quebra de privacidade. Lá onde é praticamente impossível obter-se a privacidade física, o resguardo do nome preenche o espaço da preservação por excelência da intimidade de uma pessoa. Assim sendo, os nomes sanumá só se transformam em dispositivos de classificação social à custa de anular o recato pessoal.

Isto não quer dizer que não se saiba o nome de todos os parentes, vizinhos e conhecidos num raio de vários quilômetros. Mas, ao contrário do argumento da missionária-enfermeira para justificar a própria gafe, o fato de todos saberem os nomes de todos não é o que mais interessa: o que importa é fazer de conta que não sabem. Afinal, passei meses a fio perguntando e recebendo respostas sobre nomes de centenas de pessoas com pouquíssima resistência por parte de minhas interlocutoras sanumá (sobre este assunto trabalhei exclusivamente com mulheres). A precaução a tomar é nunca perguntar diretamente sobre o próprio nome e o dos parentes próximos. A distância social e física dilui muito o sigilo. Também as crianças, como no caso do jogo agonístico das duas meninas, são grandes arautos de nomes, para minha satisfação etnográfica. Mas não se pense que eu saí incólume de minhas indiscreções onomásticas. Aquele ente malévolo que se compraz em transcrever os nomes dos viventes para matá-los tem uma inquietante semelhança com esta etnógrafa, o que não me enche exatamente de orgulho moral.

\section{DAR NOMES}

Uma pessoa sanumá pode ser nomeada poucos dias depois do nascimento ou em qualquer momento de sua vida. Pode ter seu primeiro nome revogado e substituído por outro, ou pode acumular vários ao longo da vida. Em outra ocasião (Ramos 1974) descrevi com detalhes os diversos mecanismos de aquisição de nomes pessoais e como estes estão ligados às condições de saúde da pessoa, à situação de sua família e ao contexto social da aldeia onde nasceu. Por ora basta delinear brevemente o material semântico com o qual se produzem os nomes.

Características físicas da criança podem servir de inspiração onomástica. Por exemplo, Walalamï é um nome relativamente comum dado a pessoas com olhos claros (walala), ou alguma condição persistente, como estar febril (̌̌obi); algum evento marcante por ocasião do nascimento, como Waikia, devido à rara visita dos longínqüos Waikia dïbï, ou algum incidente já na vida adulta, como Lalawa, em referência ao corte em forma de cobra, lalagïgï, que o dono do nome sofreu durante um duelo. O que transparece nesse sistema onomástico é um registro, ou melhor, um arquivo de fatos e acontecimentos que ficam marcados na memória coletiva e que vêm à tona, direta ou indiretamente, sempre que algum nome pessoal é evocado. Reminiscente da prática das mulheres Lugbara da África, que registram suas frustrações virilocais nos nomes dos seus 
filhos (Middleton 1961), verdadeiros desabafos contra sogras e maridos mal amados, o modo de nomear sanumá opera como se fosse um antídoto contra o esquecimento cultivado e a obliteração da história que caracteriza o ethos yanomami. Os nomes pessoais seriam, então, âncoras do tempo, parafraseando Keith Basso (1988) em sua magnífica análise de toponímicos apache.

Mas o sistema onomástico sanumá tem nuances muito mais sutis e socialmente conseqüentes do que lutar contra o olvido e a invasão de privacidade. O sigilo dos nomes é em si um fenômeno que, aos olhos ocidentais, deve ser bem explicado sob pena de parecer um exótico contra-senso. Já a quebra do sigilo dos nomes, acrescentando mais uma volta à espiral de aparente incompreensão, justamente por isso, força-nos a buscar entender com mais empenho a constante oscilação sanumá entre a necessidade de esquecer e a vontade de lembrar.

Em análise anterior da descendência sanumá (Ramos 1995), vi-me às voltas com o desafio de dar sentido a um sistema que é patrilinear, mas luta contra a matrilocalidade, que tenta vencer as vicissitudes da diacronia, mas acaba perdendo quase sempre para os infortúnios da sincronia - a morte, os casamentos exogâmicos, os nascimentos femininos; um sistema que procura manter intacta a linearidade, mas nada pode contra os fatores que insistem em truncá-la. Muito pouco da teoria antropológica a meu dispor tem-me sido útil para entender o quebra-cabeça do sistema social sanumá. Percebi que me deparava com uma estrutura cuja inteligibilidade está no tempo e não no espaço, mas como demonstrar isso? Alguns textos deram-se a confiança necessária para continuar na trilha da temporalidade como nexo estrutural (Stirling 1965; Geertz e Geertz 1975; Sahlins 1981), mas foram os nomes próprios dos Sanumá que me abriram, primeiro, as portas da compreensão e, depois, da comunicação, pois foi preciso entender muito bem os meandros da questão antes de buscar uma maneira convincente de descrevê-los. Foram eles a minha fonte ao mesmo tempo empírica e teórica para entender a lógica da vida social sanumá. É como se eles parafraseassem Austin (1975 [1962]), mostrando-me como fazer coisas com nomes. Em suma, atribuo aos próprios Sanumá o mérito de me encaminhar para uma análise que, se não é especialmente econômica e parcimoniosa (a exemplo das charadas lingüísticas bem resolvidas), creio que tem algo de elegante ou, na pior das hipóteses, de interesse etnográfico.

\section{SUSSURROS}

Até pouco antes da puberdade, as crianças têm seus nomes livres de sigilo. Nas revoadas infantis que perambulam pela aldeia e imediações, seus nomes próprios são apregoados aos quatro ventos sem nenhum gesto de repúdio ou vergonha. Já os nomes dos adultos são, no máximo, sussurrados ao ouvido com a concha da mão como anteparo contra os curiosos. Subitamente, os nomes 
infantis silenciam... mas nem todos. Há uma seleção sutil, em parte baseada em traços de personalidade, em parte em expectativas sobre trajetórias futuras, mas o fato é que algumas pessoas, geralmente do sexo masculino, abdicam, ou as fazem abdicar, do sigilo de seus nomes que entram, definitivamente, para o domínio público.

Como se procede a essa distinção? Através da tecnonímia. Na infância, alguns nomes de meninos e meninas são usados para nomear seus parentes imediatos, não apenas pai e mãe. O resultado é algo como isto: Ilo, Pai de Ilo, Mãe de Ilo, Irmão Mais Velho de Ilo, Irmão Mais Novo de Ilo, Irmã de Ilo. Ilo cresce e pode ou não continuar a ser o referente tecnonímico. Se continuar, gera as seguintes combinações: Mulher de Ilo, Filho de Ilo, Filha de Ilo. Ou seja, apenas os consangüíneos imediatos e os cônjuges são agrupados onomasticamente em torno de um referente. Existe, de fato, uma espécie de distribuição complementar (de novo, a lingüística como inspiração) segundo a qual o referente da família de orientação não é o mesmo da família de procriação. Quando o referente tem seus próprios filhos, um destes, provavelmente, assumirá o papel que era de seu pai. Em algumas circunstâncias de migração, certos homens forasteiros acabam sendo referentes de suas famílias de procriação, que é uma maneira de integrá-los ao novo local de residência onde vivem na desconfortável condição de afins.

São, portanto, esses referentes que indicam o caminho para que haja as condições de possibilidade que possam levar ao surgimento de um grupo patrilinear bem definido. Em outras palavras, o germe que torna possível uma linhagem é o agregado tecnonímico. O destino desse agregado tecnonímico que coincide com a família nuclear vai depender de fatores alheios às vontades dos sujeitos envolvidos. Para que vingue e se torne uma linhagem plena, é preciso haver uma massa crítica de homens vinculados agnaticamente e vivendo na mesma aldeia; é preciso que a maioria deles se case com mulheres locais e não se disperse por outras aldeias por força da residência matrilocal; é preciso que suas mulheres tenham, pelo menos, alguns filhos homens; é preciso que não haja epidemias que venham matar esse germe. Em suma, tudo conspira para que o projeto linhagem não dê certo, mas há que insistir e mantê-lo como horizonte possível. As escolhas tecnonímicas e o esforço hercúleo de resistir à força centrífuga dos casamentos exogâmicos são testemunhos desse desejo de alcançar o ideal de pertencer a uma linhagem constituída, nomeada e com a vantagem política de fornecer o líder da aldeia.

Com tantos entraves, não é de surpreender que apenas cerca de metade das pessoas tenham filiação de linhagem. Nesse jogo de azares em que agregados tecnonímicos muitas vezes se desmancham no ar antes de se delinearem em forma definitiva, resta a norma universal de pertencimento a uma outra entidade patrilinear, também nomeada, mas difusa, dispersa e sem qualquer conotação política, a que tenho dado o nome um tanto desajeitado de sibs. 
A tecnonímia é, portanto, um tipo de crônica de linhagens anunciadas que podem ou não vir a acontecer. As vicissitudes que afetam os nomes pessoais seguem de perto os altos e baixos que afetam os grupos patrilineares. Tragédias pessoais que resultam na perda de um nome refletem-se na frustração de linhagens abortadas. Vários agregados promissores nos anos 60 e 70 reduziram-se, 30 anos depois, a meros apêndices de outros agregados mais fortes ou de linhagens em curso. É como se a vontade de prosseguir no tempo fosse constantemente ameaçada por fatores espaciais. Neste sentido, a tecnonímia representa ao mesmo tempo o papel de âncora temporal - base para o devir de uma linhagem - e âncora espacial - base para a estabilidade social e política de uma linhagem.Transformados em ferramentas sociais, os nomes sanumá são capazes de marcar o domínio público com recursos da esfera privada. No entanto, isso não se faz sem reservas emocionais nem complexidades epistemológicas. Os nomes são secretos, mas alguns são revelados; são privados, mas alguns são públicos. O uso social que os Sanumá fazem de seus nomes próprios desvela um sentido de conceitualização tão refinado que, para lhe fazer justiça, é preciso apelar para um instrumento teórico ocidental igualmente complexo. Descrever meramente como os nomes são escondidos e exibidos correria o risco de se ficar aquém do refinamento sanumá e cair na armadilha da exotização. E aqui Derrida vem em meu socorro.

\section{SOB RASURA}

Em outra ocasião (Ramos 1995), chamei atenção para uma passagem no prefácio de Gayatri Spivak ao livro Of Grammatology de Derrida. Diz ela: "Ao examinar coisas estranhas chegamos a conclusões tão curiosas que tornam a nossa própria linguagem distorcida e dobrada, mesmo quando nos guia. Escrever 'sob rasura' é a marca dessa contorção" (1976: xvi). Em que consiste escrever sob rasura? No formato gráfico da escrita, passa-se um X sobre a expressão que se quer analisar, como que pondo-a entre parênteses. Uma palavra sob rasura não deveria ser mencionada, mas é preciso mencioná-la se quisermos transmitir a mensagem em jogo. Sem ela, a idéia a ser transmitida fica incompleta ou não faz sentido. Porém, ao mesmo tempo, essa mesma palavra é suficientemente problemática para ser evitada. Isto se agrava quando tratamos de coisas estranhas, não familiares, como é o caso de uma análise etnográfica sobre uma realidade distante da nossa. No limite da necessidade de comunicação dentro de um contexto de proibição, como é o caso dos nomes sanumá, é como se os Sanumá recorressem ao dispositivo de pôr certos nomes sob rasura, ou entre parênteses; é como se esses nomes, de fato, não estivessem lá, mas é inevitável que estejam. É, como diz Derrida, o traço, o rastro do nome que fica para que seja dito o que se quer dizer. Assim como Derrida propõe que o rastro é a marca lingüística da ausência de uma presença, eu sugiro que os nomes 
pessoais sanumá são as marcas da presença camuflada da família nuclear e da ausência das desejadas, mas ainda inexistentes, linhagens. Deste modo, os nomes pessoais ficam entre parênteses, sob rasura, uma rasura, no caso em questão, que é fonológica e não gráfica, pois ocorre na fala e não na escrita. Os nomes são os rastros individuais de coletividades passadas, presentes e futuras. Derridianos sem o suspeitar, os Sanumá põem seus nomes pessoais sob rasura: são impronunciáveis, mas é preciso pronunciá-los. Ao cobri-los com o silêncio protetor, eles criam com seus nomes uma linguagem própria capaz de marcar um processo social. Trata-se de linguagem que contém tantas leituras quantos forem os leitores.

É na tecnonímia que a prática da rasura fica mais evidente. Ao violar o silêncio de certos nomes próprios, a tecnonímia rouba das pessoas o seu bem mais reservado. Leva-as a abdicar de seu foro íntimo, por assim dizer, em benefício da coletivadade de seus parentes. Ao fazer a passagem dos nomes individuais para os nomes grupais, os Sanumá põem em movimento uma complexa operação: primeiro, nomeiam uma pessoa; segundo, proíbem que o nome seja pronunciado em público; e, terceiro, suspedem a proibição. Assim, o nome fica liberado para se transformar em patronímico que, por sua vez, toma a forma de um conceito a serviço do ordenamento social. É o conceito de patrilinearidade. A pessoa torna-se, assim, o traço, o rastro da coletividade quando seu nome é marcado para rasura. $\mathrm{Na}$ ausência de recursos gráficos, é por meio dessas marcas pessoais que o idioma sanumá faz suas notações coletivas. Por exemplo, há três décadas, os õkobïdili dïbï eram um grupo de irmãos uterinos com grande potencial de crescer e se transformar numa linhagem que seria conhecida como õkobïdili dïbï. Neste sentido, o rastro entre parênteses (õkobïdili dïbï) é a marca de algo que ainda não existia, ou seja, da ausência de uma presença (a linhagem õkobïdili dïbï ainda por vir). Não se deve pronunciar o nome ôkobïdili, mas é imperativo que ele seja pronunciado se se quiser marcar a potencialidade desse novo grupo patrilinear. Portanto, faz-se a passagem do campo individual ao coletivo tirando-se de um homem aquilo que lhe é mais íntimo, que é o seu secreto nome. Mas há sempre o consolo de saber que não se pronuncia esse secreto nome em vão. Entre os Sanumá, como alhures, a sociedade demanda que figuras públicas abram mão de sua privacidade e um epônimo de linhagem é verdadeiramente um homem público.

A passagem dos nomes individuais para os nomes coletivos é também a passagem da memória individual para a coletiva. A memória social retém os nomes próprios quando eles se transformam em nomes públicos, seja de grupos formados no passado, seja daqueles ainda por vir. Fora isso, os nomes individuais, conhecidos ou não, estão fadados ao destino comum de cair em desuso até serem sugados pelo esquecimento. 


\section{CODA: NOVOS TEMPOS, VELHAS MARCAS}

Com a chegada de ondas diversas de forasteiros conquistadores, nomes estrangeiros começaram a entrar no léxico social dos Sanumá. A novidade foi introduzida para o benefício dos não indígenas, seja por incompetência lingüística, seja por convicção ideológica. Primeiro foram os missionários protestantes, com seus Davis e suas Saras. Depois vieram os garimpeiros e outros aventureiros da mata, com seus regionalismos e alcunhas idiossincráticas - Ceará, Paraíba, Chileno, Passarão... De certo modo, essa nova onomástica acabou beneficiando também os Sanumá, pois os nomes vindos de fora ajudaram a aliviar a pressão sobre a quebra de sigilo dos seus nomes pessoais, contribuindo substancialmente para que estes continuassem protegidos da exposição ao ouvido público. Em contextos de atendimento médico, especialmente nos trágicos anos 90, quando a alucinada corrida do ouro que grassou pela Terra Indígena Yanomami, gerando contínuas e devastadoras epidemias de malária (Ramos 1991; 1996; 1998), era imprescindível registrar o nome de todos para controle de lâminas de sangue e de medicamentos. Quando havia nomes em língua portuguesa, esse processo era muito mais suave e ágil, em contraste com o complicado embaraço provocado pela revelação de seus próprios nomes aos membros das equipes médicas, ilustres desconhecidos em quem os Sanumá não tinham nenhuma razão para confiar. Com o crescente acervo de nomes portugueses, ao menos para uso externo, não é mais preciso sussurrar nomes para identificar as pessoas. Em tese, elas já poderiam ser chamadas aos gritos sem lamentos nem aflições.

Mas, será tão simples assim? Poucas coisas neste mundo são tão claras como parecem à primeira vista e o sistema de nomeação sanumá não é diferente. Quando pensávamos que os nomes portugueses seriam para os Sanumá um refúgio onomástico em que tensões e temores ligados a crenças ancestrais ficassem de fora, eles nos surpreendem com reações inesperadas, como a da mulher madura que esbravejou, ofendida, ao ouvir seu nome português chamado em público por uma auxiliar de enfermagem no posto de saúde da aldeia; ou como a do jovem adulto que relutou, constrangido, em assinar seu nome português num recibo por serviços prestados à etnógrafa (comunicação pessoal de Silvia Guimarães). Estaríamos então diante do mesmo princípio que rege os nomes do vernáculo sanumá? Haveria uma espécie de gradação de ofensa no desvelar de todos esses nomes? Seria o mesmo sentimento de vergonha e indignação distribuído, embora desigualmente, por nomes sanumá e nomes estrangeiros? Ou será que, uma vez plenamente incorporados ao cotidiano das pessoas, os novos nomes de branco acabam sendo assimilados ao cânone do sigilo? Se assim for, temos aí um interessante caso de preservação de conceitos (ou seja, a velha langue) em meio à renovação do léxico (a também saussuriana parole). Poderíamos mesmo, se fosse apropriado neste contexto, especular sobre 
as conseqüências disso para a trajetória interétnica dos Sanumá: quanto mais expostos ao mundo dos nomes mundanos, mais fechados em seu sigilo protetor. Quanto à organização social vigente, poderiam esses nomes estrangeiros algum dia servir de epônimos nos moldes dos nomes tradicionais, produzindo, por exemplo, um agregado tecnonímico ou mesmo uma linhagem identificada como Filipi dïbï ou Mateusi dïbï? Minha intuição auditiva diz que não, mas talvez esta reação fonológica não seja mais do que um recalcitrante e injustificável saudosismo de minha parte.

Tão ou mais frustrada do que os leitores estou eu, com tantas perguntas no ar. Como nada substitui a pesquisa de campo, a interlocução direta com os próprios Sanumá, a vivência dos contatos imediatos, resta-me apenas aguçar o interesse da nova geração de etnógrafos para esse fascinante mundo dos nomes que, como na fantasia de Jorge Luis Borges, parece ter a capacidade de se desdobrar em infinitos caminhos que se bifurcam.

A distância cultural que existe entre os Sanumá e nós garante que busquemos algo mais por trás das aparências, já que estas, freqüentemente, fazem pouco sentido em si mesmas. Porém, se a antropologia aprendeu alguma coisa nestes mais de cem anos de sua existência, é que o estranhamento que vem naturalmente quando nos enfronhamos numa realidade tão diversa pode se tornar um recurso metodológico para estranhar o que nos é naturalmente familiar. Aplicar tal recurso à onomástica lusófona pode trazer - e traz - surpresas como as que compõem este volume. É também por isso que estou aqui.

\section{BIBLIOGRAFIA}

ALBERT, Bruce, 1985, Temps du Sang, Temps des Cendres: Représentation de la maladie, système rituel et espace politique chez les Yanomami du sud-est (Amazonie brésilienne), tese de doutorado, Université de Paris X.

AUSTIN, John, 1975 [1962], How to Do Things with Words. Cambridge, Harvard University Press.

BASSO, Keith, 1988, “'Speaking with names’: Language and landscape among the Western Apache”, Cultural Anthropology, 3 (2), pp. 99-130.

CHAGNON, Napoleon, 1968, Yanomamö: The Fierce People. Nova Iorque, Holt, Rinehart and Winston.

DERRIDA, Jacques, 1976, Of Grammatology. Baltimore, Johns Hopkins University Press.

GEERTZ, Hildred, e Clifford Geertz, 1975, Kinship in Bali. Chicago, University of Chicago Press. 
GUIMARÃES, Silvia M. F., 2005, “Cosmologia Sanumá: o xamã e a constituição do ser”, tese de doutorado, Departamento de Antropologia, Universidade de Brasília.

MIDDLETON, John, 1961. "The social significance of Lugbara personal names", Uganda Journal, 26 (1), pp. 34-42.

RAMOS, Alcida Rita, 1998, Indigenism: Ethnic Politics in Brazil. Madison, University of Wisconsin Press.

—, 1996, "O papel político das epidemias. O caso Yanomami”, em Miguel Bartolomé (ed.), Ya No Hay Lugar para Cazadores. Proceso de extinción y transfiguración cultural en América Latina, pp. 55-89. Quito, Biblioteca Abya-Yala.

—, 1995, Sanumá Memories: Yanomami Ethnography in Times of Crisis. Madison, University of Wisconsin Press.

—, 1991, "Auaris revisitado", Urihi, n. ${ }^{\circ}$ 15, Boletim da CCPY - Comissão pela Criação do Parque Yanomami, São Paulo.

—, 1974, "How the Sanumá acquire their names", Ethnology, 13, pp. 171-85.

SAHLINS, Marshall, 1981, Historical Metaphors and Mythical Realities. Ann Arbor, University of Michigan Press.

SPIVAK, Gayatri Chakravorty, 1976, “Translator's preface”, em Jacques Derrida, Of Grammatology, ix-xc. Baltimore, Johns Hopkins University Press.

STIRLING, Paul, 1965, Turkish Village. Londres, Weidenfeld \& Nicolson.

\footnotetext{
Sanumá names between cries and whispers - Alcida Rita Ramos - Universidade de Brasília, pesquisadora do CNPq • alcida.ramos@uol.com.br/arramos@unb.br

Like the other Yanomami Indians, the Sanumá (the northermost subgroup of this Amazon language family) preserve their personal names in secrecy. But, unlike most Yanomami, they suspend this secrecy when it is necessary to "do things with names", to paraphrase J. L. Austin. Personal names, transformed into social tools, are capable of marking the public sphere with devices coming from the private realm. In this way, a few male names lose their secrecy so as to herald the emergence of new patrilineal groups with which the Sanumá organize their marriage and political life. With the arrival of outsiders, foreign names made their entrance in the Sanumá social lexicon, thus relieving the pressure over name secrecy. First came protestant missionaries with the Davids and Sarahs, then gold miners and other jungle adventurers with their regional and idisioncratic nicknames - Ceará, Paraíba, Passarão, etc. - greatly contributing to keep Sanumá personal names away from the public ear. It would thus seem that whispering would no longer be necessary, and crying out people's names could be done at ease. Things, however, are not as they seem. To what extent Sanumá naming etiquette has reacted to these changes is what I intend to scrutinize.
}

KEYWORDS: Yanomani, Sanumá, names, social organization, interethnic contact. 